\title{
Prevalence of ticks on local and crossbred cattle in and around Asella town, southeast Ethiopia
}

Tamiru Tessema ${ }^{1}$ and Abebaw Gashaw ${ }^{2}$

${ }^{1}$ Amber Animal Health Department, East Gojjam Agricultural Office

${ }^{2}$ College of Agriculture and Veterinary medicine, Jimma University, P.O. Box 307

Email: abebawg2002@yahoo.com or abebaw.gashaw@ju.edu.et

\section{Abstract}

The prevalence of bovine tick species in and around Asella town was studied over a period of eight months from October 2007 to May 2008. Adult ticks were collected from 384 local and crossbred cattle which were kept under extensive management system and at different agro-ecological zones. A total of 6298 adult ticks were collected from half body part of cattle, and were identified to genera and species level. Five tick species of four genera were identified, in which two species belong to genus Amblyomma, and one species each in the genus Boophilus, Rhipicephalus and Hyalomma. Of all the total ticks collected, Amblyomma, Rhipicephalus, Boophilus and Hyalomma constituted $60.1 \%, 22 \%, 15.4 \%$ and $2.5 \%$, respectively. The tick species encountered were A. variegatum (48.2\%), Rhipicephalus evertsievertsi (22\%), Boophilus decolaratus (15.4\%), A. cohaerence (11.9\%) and Hyalomma marginatum rufipes (2.5\%). The burden of ticks on cattle had statistically significant difference $(\mathrm{P}<0.05)$ between local (mean=13.1 tick/head) and crossbreed (mean=21.4 tick/head) cattle, and between cattle found in highland (mean=13.1 tick/head) and midland (mean=21 tick/head) areas of the region. The results indicated that the favorable predilection sites of Amblyomma species are ventral body part and hoof. B. decolaratus prefer dewlap, head and back. Adult R. evertsi-evertsi and $\mathrm{H}$. marginatum rufipes had a strong predilection for tail as well as ano-vulva areas. The sex ratios of all tick species identified were skewed towards male except for B. decolaratus. Further studies on factors affecting tick burden and tick control strategies are recommended.

Keywords: Ethiopia, Asella, cattle tick, predilection site, highland, midland 


\section{Introduction}

Cattle play a significant role in the socio-economic life of the people of Ethiopia. In addition to the products of meat and milk cattle provide draught power for cultivation of the agricultural lands of many peasants. Skins and hides are also important components of the livestock sector in generating foreign export earnings.

Although, only relatively few of more than 889 species of tick in the world are important to man and his domestic animals, these few species must be controlled if livestock production is to meet world needs for animal protein Drummond, (2007). Over 79 different species are found in eastern Africa but many of these appear to be of little or no economic importance Cumming, (1999). In Ethiopia, there are 47 species of ticks found on livestock and most of them have importance as vector and disease causing agents and also have damaging effect on skin and hide production Kassa Bayu (2005). Ticks, besides being important vectors for diseases like theilerosis, anaplasmosis, babesiosis and rickettsiosis (heart water) in domestic animals; they also cause non specific symptoms like anemia, dermatosis, toxicosis and paralysis Solomon Gebre et al., (2001).

In Ethiopia ticks are common in all agro ecological zones of the country Pegram et al., (1981). Therefore, relevant data on the distribution of ticks is essential for the development of effective tick and tick borne disease control strategies. Studying ticks on livestock under their natural conditions without any control measure is also useful for understanding the host parasite relationship and variation of tick population in different agro-ecological zone.

Different tick species are widely distributed in Ethiopia and a number of researchers reported the distribution and abundance of tick species in different parts of the country. Amblyomma tick is one of the most abundant tick genera and has been reported in many parts of the country, such as Bedelle Etsay Kebede (1985), Nekemte Belete Mekuria (1987), Hararghe Guliat Asrat (1987), Asella Behailu Assefa (2004), Awassa Mehari Birhane (2004), Mizan Teferi Seid Belay (2004), and Jimma Yitbarek Getachew (2004), with highest prevalence rate. Rhipicephalus is also predominant genera and has been reported with highest prevalence in GamoGofa Jewaro Abdo (1986), Bale Dejenu Gardie 1988) and Southern Sidamo Sebsibe Birru (1988). 
Although Amblyomma and Rhipicephalus ticks are predominating in many parts of the country, Boophilus and Hyalomma ticks also have a significant role. The population changes of tick are influenced by climatic changes, which affect the rate of tick population on the ground, host resistance and natural enemies Solomon Gebre et al., (2001). Amblyomma cohaerence is prevalent and abundant in western humid highland areas of Ethiopia. Boophilus decolaratus and Rhipicephalus evertsi evertsi are widely distributed in most altitudinal ranges Bekele Hailu (1987).

The objective of this study was to determine the prevalence of tick species, Identify the favorable predilection sites of ticks and to measure the tick burden within breeds, different age groups and agro-ecological zone in Asella town and its surrounding peasant associations.

\section{Materials and Methods}

Study area

Asella, a capital of Arsi zone, is under the administration of the Oromyia National Regional state. Asella town is located about $175 \mathrm{~km}$ Southeast of Addis Ababa. The area comprises mid land area with an altitude of 1800- 2500 and high land area 2500-4130 meter above sea level (masl). The annual mean rainfall ranges from 2000 to $4000 \mathrm{~mm}$ and annual ambient temperature varies from $20^{\circ} \mathrm{C}$ to $30^{\circ} \mathrm{C}$. Tick collection sites were identified in collaboration with Tiyo woreda district veterinary personnel.

Study animals

Cattle found in Asella town and nine peasant associations surrounding Asella were the target animals. The livestock population of the area comprised about 82190 cattle, 51292 sheep, 11479 goats, 22055 equines and 162015 poultry. Three hundred and eighty four local and cross breed cattle, infested with ticks, were purposively selected and examined for the distribution and abundance of ticks. All cattle sampled for this study were kept under extensive management system. The sampled animals were not treated with any acaricide for all the months at the time of study.

Cross-sectional study design was implemented to determine the distribution of tick species, favorable predilection sites and the tick burden within a group of breeds, ages and agro-ecological zones in Asella town and its surrounding peasant associations. 
The sample size was determined by assuming the expected prevalence of $50 \%$ tick infestation (no previous prevalence of cattle tick infestation in Asella town). The desired sample size for the study was calculated using the $95 \%$ confidence interval and at 5\% absolute precision Thrusfield, (1995). Therefore, a sample size of 384 cattle (233 indigenous and 151 crossbred cattle) was examined in this study. The sample was taken by using purposive sampling. Cattle were categorized based on age (<1yr, 1-3yrs and >3yrs), breed (local and cross) and location (highland and midland).

Study period, tick collection and identification methods

Ticks were collected from half body of animals using forceps at eight main body sites from October 2007 to May 2008. Adult ticks collected from each of eight main body sites were preserved with pre-filled $68 \%$ methanol in universal bottles separately. Date of collections, place of collections, body sites of collection, and breed of host were recorded. Counting, identification and recording took place within 10 days of collection. The taxonomic key of Hoogstraal, (1956), Walker, (1974) and Kaiser, (1987) were used to identify ticks under Stereomicroscope.

For analysis the half body tick counts were doubled to obtain whole body tick burden. All data recorded in this study were entered into Microsoft excel and subsequently analyzed using SPSS computer program. Chi-square test was used to determine the variation in tick burden between different groups of breeds, age and agro-ecological zone. Descriptive statistics was also used to show favorable predilection sites of tick species.

\section{Results}

A total of 6298 ticks were collected from which four genera and five species were identified. Amblyomma (60.1\%) was the most abundant and widely distributed genus in all study sites and Hyalomma (2.5\%) was the least prevalent tick genus identified (table1).

Table 1.Distribution of tick genera of cattle in and around Asella town, Ethiopia.

\begin{tabular}{lc}
\hline Genus & $\%$ of the total ticks \\
\hline Amblyomma & $60.1 \%$ \\
Rhipicephalus & $22 \%$ \\
Boophilus & $15.4 \%$ \\
Hyalomma & $2.5 \%$ \\
\hline
\end{tabular}


In this study A. variegatum was the most abundant tick species and it represented $48 \%$ of the total ticks collected. This tick species was found in all study sites. Heavy infestation of A. variegatum were recorded in mid altitude areas. R. evertsi-evertsi was the second most abundant and widely distributed tick species. This species represented $22 \%$ of the total collection of ticks. R. evertsi-evertsi was founded in all study sites and collected from an altitude range between 1850 and 2950 masl.

B. decolaratus was the third widely distributed tick and has got similar distribution pattern to that of $A$. variegatum. It represented $15.4 \%$ of the total collection of ticks. A. cohaerence was the fourth most common tick species and it was widely distributed in wetter highlands and collected between 2200 and 2950 masl. H. marginatum rufipes was the least abundant tick species (2.5\%) and it was collected from restricted area of warm, moderately dry mid lands between 1800 and 1950 masl. At genus level the male to female ratio was Amblyomma 3.2:1, Boophilus 0.4:1, Rhipicephalus 1.2:1 and Hyalomma 2.4:1.

The results of the study indicated that the most favorable predilection sites for Amblyomma species and $\mathrm{H}$. marginatum rufipes were the ventral body parts (Udder/scrotum, axillae, belly and groins) and hoof. B. decolaratus was collected mostly from dewlap, head and back but was also present on the rest of the body. Adult R. evertsi- evertsi had a strong predilection for smooth skin under the tail as well as peri- anal and vulval areas (table 2).

Table 2. Distribution of tick species, favorable predilection site and their sex ratio collected in and around Asella, Ethiopia.

\begin{tabular}{lcccl}
\hline Tick species & Total tick & \% out of total & $\begin{array}{c}\text { Sex ratio } \\
\text { (male: female) }\end{array}$ & $\begin{array}{l}\text { Predilection } \\
\text { sites }\end{array}$ \\
\hline A. variegatum & 3038 & $48.2 \%$ & $3.7: 1$ & venter, hoof \\
R. evertsi-evertsi & 1388 & $22 \%$ & $1.2: 1$ & Ano-vulva, tail \\
B. decolaratus & 972 & $15.4 \%$ & $0.4: 1$ & dewlap, head, back \\
A. cohaerence & 746 & $11.9 \%$ & $2.7: 1$ & venter, hoof \\
H. marginatum rufipes & 144 & $2.5 \%$ & $2.4: 1$ & Hoof, venter \\
\hline
\end{tabular}

The difference in tick burden between cattle of midland altitude and highland area was founded to be significant $\left(P=0.000, X^{2}=77.029\right.$, df $\left.=27\right)$ higher values being recorded in cattle from midland altitude ( 21 tick /head) than those from the highland areas (13.1 tick/head). Similarly from the two breed of cattle, crosses (21.4 tick/head) were found to have more $\left(P=0.000, X^{2}=61.344\right.$, df $\left.=27\right)$ 
tick burden than local cattle (13.1 tick/head). The effect of age on the burden of tick was not significant $\left(P=0.433, X^{2}=55.095, d f=54\right)$ (table 3$)$.

Table.3. Tick burden within group of breed, age and altitude in Asella, Ethiopia.

\begin{tabular}{lccccccc}
\hline & \multicolumn{2}{c}{ Breed } & \multicolumn{2}{c}{ Age } & \multicolumn{2}{c}{ Altitude } \\
\cline { 2 - 7 } & Local & Cross & $<1 \mathrm{yr}$ & 1 -3yrs & $>3 y r s$ & Midland & Highland \\
\hline $\begin{array}{l}\text { No. of animals } \\
\text { examined }\end{array}$ & 233 & 151 & 88 & 153 & 143 & 159 & 225 \\
Total tick collected & 3062 & 3236 & 1440 & 2784 & 2074 & 3346 & 2952 \\
Mean tick burden & 13.1 & 21.4 & 16.4 & 18.2 & 14.5 & 21 & 13.1 \\
\hline
\end{tabular}

\section{Discussion}

The distribution and abundance of the most common tick species infesting cattle in Ethiopia vary greatly from one area to another. In this study A. variegatum were found to be most abundant tick species in Asella region (48.2\%) and similar results have been reported by Tesfanesh Gebremichael (1993) in North Omo, Mehari Birhane (2004) in Awassa and Behailu Assefa (2004) in Asella. A. variegatum is the most widely distributed cattle tick in Ethiopia Morel, (1980); Pegram et al., (1981) and has a great economic importance, because it is an efficient vector of Cowdria ruminatum, the organism causing cowdrosis or heart water in cattle Morel, (1980). A. variegatum also causes the greatest damage to hides and skins because of its long mouth part which renders the commodity valueless on world market if the infestation is high Solomon et al., (2001). Furthermore, ulcer caused by this tick species becomes favorable site for secondary bacterial infection like Dermatophilus congolensis.

Rhipicephalus evertsi-evertsi was second abundant (22\%) and widely distributed tick species in this study. This tick species was also reported to be prevalent in Awassa Mehari Berhane (2004) and Asella Behailu Assefa (2004). Morel (1980) affirmed that the native distribution of R. evertsi-evertsi in Ethiopia seems to be connected with middle height dry savannas and steppes in association with Zebra and ruminant and it is widely distributed throughout Ethiopia. This tick species shows no apparent preference for particular altitude, rainfall zones or seasons Pegram et al., (1981).

Boophilus decolaratus, the third abundant tick species (15.4\%), has also been reported in many parts of Ethiopia, such as in Rift Valley Solomon Gebre et al., (2001), Hararghe Gulilat Asrat (1987), Bale Dejenu Gardie (1988), in the highland areas of Harar and Dire Dawa districts Mannueri and Tilahun Jiffar 
(1991) and in Girana valley of North Wollo Seyoum Zenebe (2001). Contrary to our results, Morel, (1980) stated that B. decolaratus is often collected in Ethiopia and does not seem really abundant any where. This tick species is abundant in wetter highlands and sub-highlands receiving more than $800 \mathrm{~mm}$ rainfall annually Pegram et al., (1981) and has similar distribution to A. variegatum. B. decolaratus can transmit Babesia begmina and Anaplasma marginale to cattle, and severe tick infestation can lead to tick worry, anorexia and anemia Sileshi Mekonnen et al., (2001).

Amblyomma cohaerence was the fourth abundant tick species (11.9\%) found in the study area. However, in western Ethiopia, where the climate is humid much of the year, $A$. cohaerence is the most prevalent and abundant tick on cattle Pegram et al., (1981). In tick survey conducted in western Ethiopia, A. cohaerence was founded to be the most prevalent in Mezanteferi Seid Belay (2004) and Jimma Yitbarek Getachew (2004) with a prevalence rate of $50.5 \%$ and $83.1 \%$, respectively.

H. marginatum rufipes was the least abundant tick collected and represented $2.5 \%$ of the total counts. This tick species was collected from restricted areas of warm, moderately dry mid lands between altitudes of 1800 to 1950 masl. Hoogstraal, (1956) stated that H. marginatum rufipes is widely distributed in the most arid parts of tropical Africa, receiving 250 to $650 \mathrm{~mm}$ annual rainfall and his results concur with our findings.

A verity of factors such as host density, interaction between tick species, time and season, and inaccessibility for grooming determine the attachment site of ticks (Solomon Gebre et al., 2001). The predilection sites found in this study corroborate with those reported by other authors Seyoum Zenebe (2001); Behailu Assefa (2004).

The male to female rations of $A$. variegatum, $R$. evertsi-evertsi, B. decolaratus, A. cohaerence and $\mathrm{H}$. marginatum rufipes were similar to previous reports Seyoum, Zenebe (2001); Solomon Gebre et al., (2001). Except B. decolaratus, all other species of tick's males out numbered females because males normally remain on the host longer than females. Fully engorged female tick drops off to the ground to lay eggs while male tends to remain on the host up to several months to continue feeding and mating with other females on the host before dropping off Solomon Gebre et al., (2001). The females of B. decolaratus out numbered males in this study probably due to small size of male which may not be seen during collection. 
he fact that more tick burden was recorded in the crossbred cattle compared to local cattle would help in planning for tick control before the introductions of different improved breeds. In the past, attempts to introduce cattle of exotic inheritance in to tropics have not had the success expected. One reason for the failure could be because of the high susceptibility to tick and tick-borne diseases of exotic and improved breeds. However, the fear of introducing susceptible cattle can be solved by introducing certain degree of resistance in these cattle by means of prophylactic treatment before introduction into enzootic area Solomon Gebre et al., (2001).

The variation in tick burden between midland altitude and highland cattle might be due to tick activity influenced by rainfall, altitude and atmospheric relative humidity Pegram et al., (1981).

Acaricide usage is still the main choice of tick control in the region. Currently organophosphates acaricidies are most widely used chemicals. Chlorinated hydrocarbons have been banned, because of the threat to human health and occurrence of acaricide resistant to tick. However, organophosphate resistance is also emerging, especially in Boophilus ticks (one host ticks) it is a drug of choice in the region.

Tick control can be achieved by attacking one or more larval phases along the life cycle chain FAO, (1984). In addition to acaricide applications, appropriate livestock management, zero grazing and exploiting genetic resistance tick infestation are recommended.

Based on the findings during the study period and the information's gathered from various cattle owners', infestation rate and tick burden decrease during long dry season (January to March) and increases after short rainy season (May to June).

\section{Recommendation}

The study indicated that there was high burden of ticks in the area. However, the attention given to control the infestation had not been sufficient. Acaricide application is the main method of tick control in the region.

Tick should be managed at an economically acceptable level by a combination of techniques and this requires knowledge of the tick species prevalence and an understanding of their epidemiology. Because there is no single method that would guarantee complete control of ticks and tick borne diseases, com- 
bination of available methods of tick control is necessary. This encompasses the selection of tick resistant cattle, acaricide treatment, appropriate livestock management, evaluation and incorporation of traditional practices or remedies that appear to be of value.

In general the distribution limits of ticks are not fixed but are determined by a complex interaction of factors such as climate, host density, host susceptibility, grazing habits and pasture-herd management. Therefore, further studies in the distribution pattern of tick species and factors responsible for their distribution are necessary for the continuous understanding of the problem and to use improved control strategies.

\section{Reference}

Abdo, J. 1986. A survey of tick and tick borne diseases in GamoGofa administrative region. DVM thesis, FVM, AAU, Debrezeit, Ethiopia.

Asrat, G. 1987. A preliminary survey of ticks on domestic animals in Hararghe administrative region. DVM thesis, FVM, AAU, Debrezeit, Ethiopia.

Assefa B. 2004. A survey of ticks and tick-borne blood protozoa in cattle at Assela, Arsi Zone. DVM thesis, FVM, AAU, Debrezeit, Ethiopia.

Bayu, K. 2005. Standard veterinary laboratory diagnostic manual. Vol. III. MOA Addis Ababa

Belay, S. 2004. Survey of cattle tick species in and Around Mizan Teferi, Bench Maji Zones of SNNPS. DVM thesis, FVM, AAU, Debrezeit, Ethiopia.

Birru, S. 1988. A preliminary survey of tick distribution in southern Sidamo DVM thesis, FVM, AAU, Debrezeit, Ethiopia..

Birhane, M. 2004. Distribution of livestock tick species in Awassa Area. DVM thesis, FVM, AAU, Debrezeit, Ethiopia.

Cumming, G.S. 1999. Host distributions do not limit the species ranges of most African ticks (Acari: Ixodida) Bulletin of Entomological Research (1999), 89:303-327

Drummond, R.O. 2007. Tick borne livestock diseases and their vector. World Animal Review 3.htm

FAO, 1984. Ticks and tick-borne disease control. A practical field manual. Vol. 1. tick control. FAO, Rome.pp.1-299. 
Garedie, D. 1988. A preliminary survey of ticks on domestic animals in Bale administrative region. FVM, AAU, Debrezeit, Ethiopia.

Gebre, S., Nigist, M., and Kassa. B. 2001. Seasonal variation of ticks on calves at Sebeta in western Shewa Zone. Ethiopian Veterinary Journal, 7 (1\&2): 17-30.

Gebremichael, T. 1993. Tick and tick borne diseases of cattle in North Omo administrative Zone, DVM thesis, Faculty of veterinary medicine, Addis Ababa University, Debrezeit, Ethiopia.

Getachew, Y. 2004. Tick species infesting livestock in Jimma area, southwest Ethiopia. DVM thesis, FVM, AAU, Debrezeit, Ethiopia.

Hailu, B. 1987. Study of the topographical distribution of tick on economically important domestic animals in Illubabor. DVM thesis, FVM, AAU, Debrezeit, Ethiopia.

Hoogstraal, H. 1956: African Ixodidae, Tick of Sudan, Cairo, Egypt, U.S Naval med. Res. Unit 3.110/p..

Kaiser, M. N. 1987. Ethiopia, Report on tick taxonomy and biology, AG:DP /ETH/83/023 Consultant report .Food and Agricultural Organization of the united Nations pp. 92.

Kebede, E. 1985. Seasonal tick population survey at Bedelle. DVM thesis, FVM, AAU, Debrezeit, Ethiopia.

Manueri, K. K. and Jiffar, T. 1991. A survey of ecto-parasites of cattle in Harer and Dire Dawa districts, Hararghe administrative region of Ethiopia. Bull. Anim. hlth and prod.30, 45-53.

Mekonnen, S., Hussein, I. and Bedane, B. 2001: The distribution of ixodid ticks in central Ethiopia. Onderstepoort journal of veterinary Research, 68 (4):243-251.

Mekuria, B. 1987. A preliminary survey of ticks on four species of domestic animals in Nekemte Awraja. DVM thesis, FVM, AAU, Debrezeit, Ethiopia.

Morel, P. 1980. Study on Ethiopia ticks (Acarida, Ixodidea) .Republic of France, Minister of Foreign affairs, Feench Vet. Mission, Addis Abeba, C.J.E.M.V.T, pp.7-332.

Pegram, G., Hoogstraal, H., and Wassef, H.Y.1981. Ticks (Acari Ixodidea) of Ethiopia Distribution, Ecology and Host relationship of species infecting livestock. Bulletin of entomology Research, 71:339-359. 
Tamiru Tessema, et al

Thrusfield, M. 1995. Veterinary Epidemiology, 2nd edition. Black well science Ltd. Oxford U.K

Walker, J. B. 1974. The Ixodidae ticks of Kenya. A review of present knowledge of their host and distribution. Common wealth institute of Entomology, London

Zenebe, S. 2001. Study of ticks and tick borne disease on cattle at Girran valley in the North Wollo Zone. Proceeding of the Ethiopian Veterinary Association,V-15. 